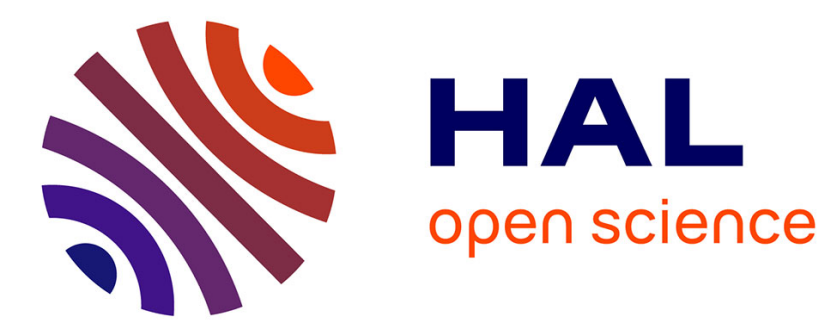

\title{
Perturbations of Electric and Magnetic Fields Due to the Presence of Materials in TEM Cells
}

Mohsen Koohestani, Mohamed Ramdani, Philippe Besnier, Jean-Luc Levant, Richard Perdriau

\section{- To cite this version:}

Mohsen Koohestani, Mohamed Ramdani, Philippe Besnier, Jean-Luc Levant, Richard Perdriau. Perturbations of Electric and Magnetic Fields Due to the Presence of Materials in TEM Cells. IEEE Transactions on Electromagnetic Compatibility, 2020, 62 (4), pp.997-1006. 10.1109/TEMC.2019.2928215 . hal-02335034

\section{HAL Id: hal-02335034 \\ https://hal.science/hal-02335034}

Submitted on 17 Jul 2020

HAL is a multi-disciplinary open access archive for the deposit and dissemination of scientific research documents, whether they are published or not. The documents may come from teaching and research institutions in France or abroad, or from public or private research centers.
L'archive ouverte pluridisciplinaire HAL, est destinée au dépôt et à la diffusion de documents scientifiques de niveau recherche, publiés ou non, émanant des établissements d'enseignement et de recherche français ou étrangers, des laboratoires publics ou privés. 


\title{
Perturbations of Electric and Magnetic Fields Due to the Presence of Materials in TEM Cells
}

\author{
Mohsen Koohestani, Senior Member, IEEE, Mohamed Ramdani, Senior Member, IEEE, Philippe Besnier, \\ Senior Member, IEEE, Jean-Luc Levant, and Richard Perdriau, Senior Member, IEEE
}

\begin{abstract}
This paper investigates in detail the impact of electric (E) and magnetic (H) field distributions inside TEM cells, below and above the corresponding dominant modes of the cells, in conditions differing from free space, i.e. in presence of representative ferromagnetic and dielectric materials. Simulations and measurements were performed from hundreds of $\mathrm{MHz}$ to $\mathrm{GHz}$ using IEC 61967-2 (closed) and open TEM cells. Whatever the frequency and EUT location, unlike dielectric material which only locally changes the norms $(\|\|$.$) of E$ (and $H$ depending on permittivity) at its location, the presence of ferromagnetic material inside the cell changes both $\|\mathbf{E}\|$ and $\|\mathbf{H}\|$ distributions: locally below the dominant mode frequency and globally at the entire bottom of the cell above that frequency. This demonstrates that a local distortion of $\|\mathbf{H}\|$-field, due to ferromagnetic material, has a stronger influence than a local distortion of $\|\mathbf{E}\|$ field, disregarding frequency, location and magnetic losses. Moreover, the demand to use a TEM cell below the dominant mode frequency, as mentioned in the IEC 619672 and 62132-2 standards, may not be relevant, provided that both EM field inhomogeneities are considered, and the presence of an IC package in the cell is accounted for in the equivalent $\|\mathbf{E}\|$-field level around the pins in immunity testing.
\end{abstract}

Keywords-closed and open TEM cells, $\|\mathbf{E}\|$ and $\|\mathbf{H}\|$ field distribution, ferromagnetic and dielectric materials

\section{INTRODUCTION}

$\mathbf{E}$ LECTROMAGNETIC IMMUNITY (EMI) and electromagnetic compatibility (EMC) characterization of integrated circuits (ICs) are of great importance as the high-speed signals not only cause signal integrity issues, but also lead to radiation and interference problems [1]-[3]. Particularly, with the fast pace of ICs technologies to reduce their sizes and/or

Manuscript received April 10, 2019.

M. Koohestani, M. Ramdani, and R. Perdriau are with ESEO, Department Electrical and Control Engineering, RF-EMC research group, Angers 49107, France, and also with the Institute of Electronics and Telecommunications of Rennes (IETR), Rennes 35042, France (e-mail: \{mohsen.koohestani, mohamed.ramdani, richard.perdriau $\} @$ eseo.fr).

P. Besnier is with the Institute of Electronics and Telecommunications of Rennes, Rennes 35042, France (e-mail: philippe.besnier@insa-rennes.fr)

J.-L. Levant is with Microchip (previously ATMEL) Nantes, 44300 Nantes, France (e-mail: jeanluc.levant@microchip.com)

at http://ieeexplore.ieee.org.

Digital Object Identifier 10.1109/TEMC.20XX.XXXXXXX. power consumption, they are more susceptible to electromagnetic (EM) disturbances and, consequently, providing good EMC characteristics is much more challenging [1], [4]. This makes the difference among IC manufacturing competitors.

Every IC package (including the pins) has conducted and radiated immunity levels, and its malfunction is subject to exposure to electric (E) or magnetic $(\mathrm{H})$ fields. Depending on the ICs internal architecture and pin couplings, EM disturbance can affect the IC performance leading to exceed the immunity levels to $\mathrm{E}$ and $\mathrm{H}$ (e.g. all microcontrollers ( $\mu \mathrm{Cs}$ ) are sensitive to both $\mathrm{E}$ and $\mathrm{H}$ with different frequency behaviors) [5]. Therefore, determining those EMC parameters helps engineers to evaluate the IC having an idea of its immunity. In parallel, ICs must not disturb other devices located on the same PCB or in the same system: consequently, their $\mathrm{E}$ and $\mathrm{H}$ emission levels must also be assessed. The international electrotechnical commission (IEC) has set standards for ICs emission (IEC 61967-2 [6]) and immunity (IEC 62132-2 [7]) testing.

Since their introduction, transverse electromagnetic (TEM) cells have been widely used for EMC/EMI emission/immunity testing of active devices to indicate the equipment under test (EUT) radiation with respect to its orientation and to frequency [8], [9]. A TEM cell approximates a uniform and linearly polarized plane wave. Generating uniform fields of known strength is important for accurate and repeatable susceptibility measurements. A TEM cell as the far-field free space condition emulator is assumed to have a uniform field distribution with the wave impedance of approximately $120 \pi \Omega$ (i.e. $\|\mathrm{E}\|$ to $\|\mathrm{H}\|$ norms ratio is $377 \Omega$ ). However, there exist several questions to be addressed.

(Q1) To what extent a TEM propagation and a wave impedance of $120 \pi$ can be assumed? (Q2) Does the EUT induce higher order modes and, in this case, how does their location influence the test? (Q3) What about the impact in IEC 61967-2 TEM cells (referred to as "closed" throughout the paper) where the EUT cannot be moved?

Electronic circuits are usually printed on dielectric materials with certain permittivity, and sometimes they are covered with ferromagnetic materials (like ferrite sheets) to improve their radiated immunity and/or emission. Moreover, in most cases, a piece of paper (having a dielectric constant of $~ 3$ [10]) is used as an insulator when placing the EUT at the bottom of open TEM cells. (Q4) What are the impacts of those materials on the EM field (both distribution and level) inside the TEM cell where the EUTs are located?

Furthermore, during our recent experiments using an open TEM cell, we noticed that the presence of our hand to change 
the orientation of the PCB hardly disturbs the received power spectrum measurements (Fig. 117). (Q5) Does this mean that a dielectric material has no influence (but local) on the $\mathrm{E}$ and $\mathrm{H}$ distributions inside the cell?

In literature, there are several works reporting information on the EM field distribution inside TEM cells [11]-[21]. However, in addition to the above-mentioned questions $(\mathbf{Q 1}$ to Q5), (Q6) the question of E- and particularly $\mathrm{H}$-field distributions as a function of frequency has not been addressed so far in TEM cells analysis, especially in presence or absence of different materials.

Insight into both $\mathrm{E}$ and $\mathrm{H}$ distribution mechanisms in TEM cell contributes to the understanding of the rationale behind the causes of susceptibility problems when they occur. In addition to that, (Q7) there is no clear reason why the center position in the cell, chosen for emission/immunity testing (according to IEC standards), would implicitly represent the optimal scenario for emission and immunity at any frequency. This information can allow the IC designer to better predict the emission/immunity of their ICs. Therefore, we would like to add our contribution to the in-depth study of EM fields inside TEM cells.

The main goal of this study is to examine these open challenges by reporting and clarifying the role of $\mathrm{E}$ and $\mathrm{H}$ distributions in TEM cells. Indeed, the correlation between those distributions and EMC/EMI properties of EUTs is of great importance as it contributes to the advancement of knowledge in the field through better understanding of EMC/EMI in emission/immunity testing scenarios. Simulations and measurements were conducted to validate the study.

The paper is organized as follows. Section II describes the materials used, the methodology employed, and the simulation and experimental setup configurations. Section III details the analysis of the numerical results, while Section IV addresses the experimental results of the proposed technique. Concluding contributions of this study are provided in Section V.

\section{Materials And Methods}

This section presents the research material and methodology to study and highlight the EM field behavior in TEM cells.

\section{A. Simulation Setup and Method}

A standard Tekbox open TEM cell (Model: TBTC1, DC up to $3 \mathrm{GHz}$ [22]) as the far-field free space condition emulator was numerically modeled using Ansys HFSS commercial fullwave electromagnetic simulation package [23] (Fig. 17a to Fig. 1 1d). All the yellow-colored metallic parts in the numerical models were considered to be copper $\left(\sigma=5.8 \times 10^{7} \mathrm{~S} / \mathrm{m}\right)$. A rigorous iterative algorithm based on mixed basis functions was used to refine the mesh, noting that mixed order efficiency is comparable or better than all single order basis functions [23].

To study the influence of the human hand on the field distributions inside a TEM cell, a high-resolution $(1 \mathrm{~mm})$ dispersive anatomical geometry of a human hand was used in simulations. The model was taken from the predefined human body exteriors in the HFSS component library [23]. It is

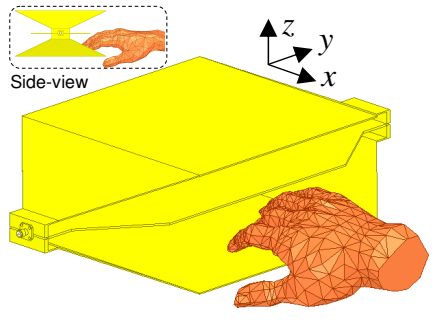

(a)

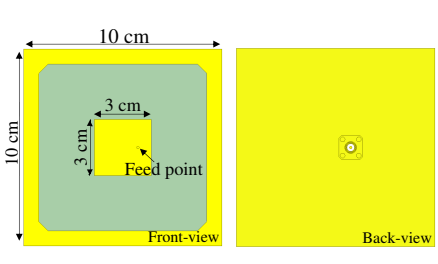

(c)

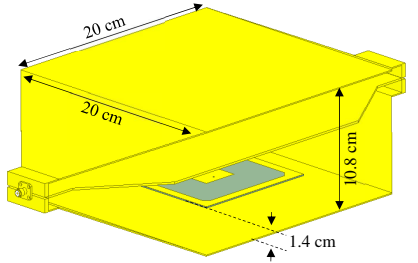

(b)

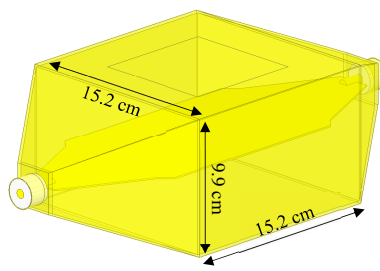

(d)

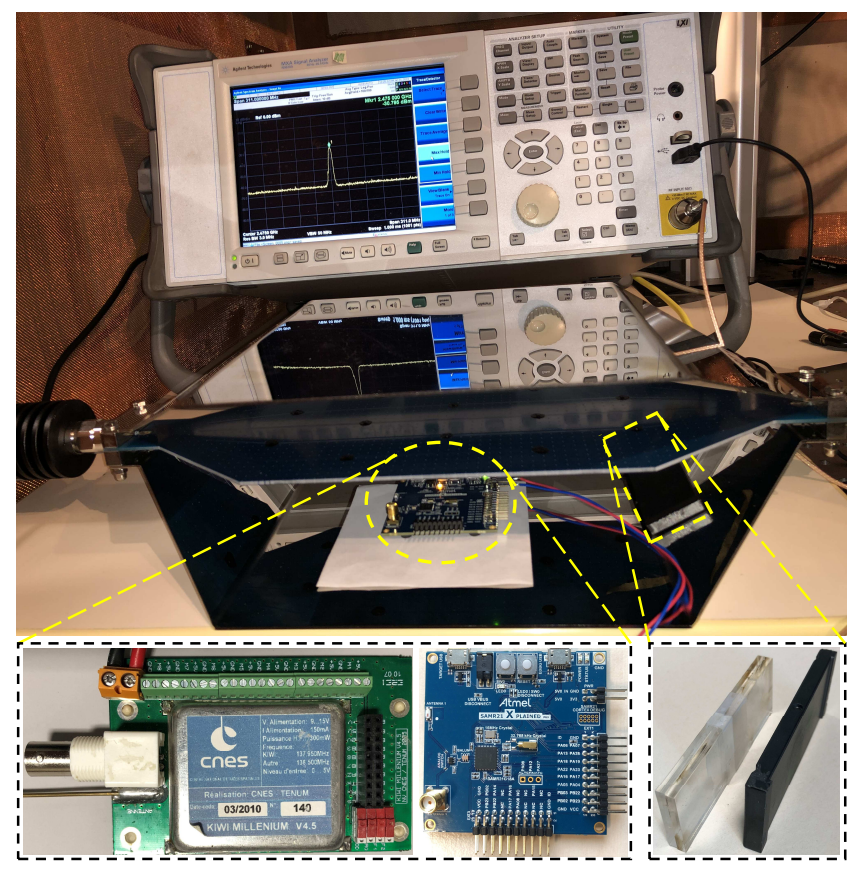

(e)

Fig. 1. Simulation and measurement scenarios: (a) an open TEM cell in presence of a dispersive anatomical human hand; (b) open TEM cell with a $2.45 \mathrm{GHz}$ patch antenna in its center; (c) patch antenna; (d) closed TEM cell; (e) open TEM cell loaded by a small piece of ferrite (to be replaced then by a Plexiglas of similar size) while measuring radiated emission of a SAMR21 $\mu \mathrm{C}$ (replacing the Kiwi Millenium transmitter) inside a Faraday cage.

homogeneous with an averaged permittivity and conductivity of hand tissues with the electrical properties taken from Gabriel's data base [24], i.e. $\varepsilon_{r}=39.2$ and $\sigma=1.8 \mathrm{~S} / \mathrm{m}$ at $2.45 \mathrm{GHz}$. In order to assess the impact of ferromagnetic and dielectric materials on the EM field relations inside the TEM cell, the latter was loaded by small pieces of ferrite $\left(\varepsilon_{r}=12, \mu_{r}=1000, \sigma=0.01 \mathrm{~S} / \mathrm{m}\right)$ and Plexiglas $\left(\varepsilon_{r}=3.4, \mu_{r}=1\right)$ of $76.2 \mathrm{~mm} \times 28.6 \mathrm{~mm} \times 6.35 \mathrm{~mm}$ dimensions (this is the size of a standard rectangular-shaped piece of ferrite with a recommended frequency range below $300 \mathrm{MHz}$ [26]. A part of this study (section III-A) was conducted using ferrites of different permittivities of 12 and 
1 as well as virtual dielectric material with $\varepsilon_{r}=1000$ while keeping their permeability unchanged.

As far as emission simulation is concerned, a narrow-band patch antenna with a $2.45 \mathrm{GHz}$ operating frequency was placed $1.4 \mathrm{~cm}$ (for the SMA connector not to touch the cell) above the bottom of the open TEM cell (Fig. 1p). The antenna consists of a $10 \mathrm{~cm} \times 10 \mathrm{~cm}$ PCB, defined in the standard [6], with a $3 \mathrm{~cm} \times 3 \mathrm{~cm}$ square metal patch coaxially-fed $8 \mathrm{~mm}$ off the center of the patch (Fig. 1 $\mathrm{k}$ ) to resonate at the frequency of interest. It was simulated on a low cost FR4 epoxy substrate $\left(\varepsilon_{r}=4.4\right.$, thickness $=0.8 \mathrm{~mm}$, and $\tan \delta=0.02)$. The other side of the PCB was coated with metal serving as ground plane. A lumped port was used as the RF power source in HFSS. The input power was changed from $1 \mathrm{~W}$ to $4.2 \mathrm{~W}$ in order to compensate for the mismatch at the actual simulation frequency $(2.475 \mathrm{GHz})$ corresponding to the emission frequency of the real device (SAMR21 $\mu \mathrm{C}$ ) used for measurement in the next subsection. Moreover, ferrite and Plexiglas were located at the bottom corner of the cell close to the input source to be able to easily move the EUT along the cell axis $y$ (in the measurement process) and to place it at the fields maximum peak and minimum null positions.

In addition, to investigate how the presence of the ferromagnetic and dielectric materials impact the field distributions in real IEC 62132-2 immunity testing inside closed TEM cells, a standard cell (FCC-TEM-JM2, DC up to $1.6 \mathrm{GHz}$ [25]) was also modeled (Fig. 11d). A PCB similar to the one used for emission testing (Fig. 11) was also considered, but with a $1 \mathrm{~cm} \times 1 \mathrm{~cm}$ patch covered by FR4 material representing an IC with its package, and no feed point.

Finally, since the claimed upper frequency of commercial TEM cells often exceeds the $150 \mathrm{kHz}$ to $1 \mathrm{GHz}$ range of IEC 61967-2/62132-2 standards disregarding the propagating modes, simulations and measurements were also considered above $1 \mathrm{GHz}$. In fact, manufacturers usually define the upper frequency of a cell only based on the VSWR value; however, that frequency is generally not known to be well above the dominant mode frequency of the cell. This leads to a possible use outside the plane wave frequency range. The current study makes it possible to assess the relevance of the instructions mentioned in the standards where the TEM cell should be always used below the dominant mode frequency.

\section{B. Measurement Setup and Method}

The standard Tekbox open TEM cell [22] was employed for the purpose of this study (Fig. 1 1 ). Two different measurements were conducted in order to investigate simulations in realistic conditions:

- within the useful frequency range of the used ferrite

- in the $2.4 \mathrm{GHz}$ band in order to assess the cell behavior at a higher frequency

All measurements were conducted inside a Faraday cage. Note that the immunity of an EUT can only be assessed by an indirect measurement based on a relevant criterion, since it is not possible to use a field probe within the cell without further disturbing the existing field. As is generally known, it is extremely difficult to identify an EUT which would be subject to a malfunction at a given frequency, as well as the associated criterion. Therefore, emission measurements were chosen to adequately support our findings from simulations.

The first measurement campaign used a "Kiwi Millenium ver. 4.5" RF transmitter used by Centre National d'Etudes Spatiales (CNES) in France for communication with sounding balloons [27]. The center frequency was $138.5 \mathrm{MHz}$, which is within the frequency range of the ferrite. The RF transmitter was powered by a $9 \mathrm{~V} \mathrm{DC}$ supply and introduced at the bottom of the open TEM cell with a paper sheet as an insulator. The emission spectrum was then measured thanks to a Keysight N9020A vector spectrum analyzer (VSA) in plain analyzer mode and peak hold detection, connected to the septum of the TEM cell with a one-meter $18 \mathrm{GHz}$ cable. The other port of the TEM cell was terminated with a $50 \Omega$ load. Three different configurations were tested:

- no other material than the EUT was introduced in the cell

- a thin piece of Plexiglas was introduced in the cell at the access near the port connected to the VSA

- a piece of ferrite of the same size as Plexiglas was introduced at the same location

The second campaign was based on the use of a SAMR21 (Microchip-Atmel) $\mu \mathrm{C}$ with a built-in $2.4 \mathrm{GHz} \mathrm{RF}$ transceiver [28]. The $\mu \mathrm{C}$ was located on a commercial Xplained Pro evaluation board with a built-in ceramic antenna (Fig. 1,). Moreover, it was programmed with a piece of software sending out frames according to the IEEE 802.15.4 protocol, with a center frequency equal to $2.475 \mathrm{GHz}$ (i.e. channel 25), and powered by a $5 \mathrm{~V}$ DC supply. The locations of peaks and nulls in the TEM cell response had been previously characterized thanks to simulation and verified with measurement. A small piece of paper was used as an insulator (Fig. 11). Then, the EUT was placed at one peak followed by one null; the former, being the worst-case scenario, would assess the true effect of the materials. The same three tests (without any material, with Plexiglas, with ferrite) were repeated with the $\mu \mathrm{C}$. Finally, to assess the impact of the paper (which is indeed an insulator with $\varepsilon_{r} \sim 3$ [10]), measurements were conducted with and without (w/o) paper. In that case, for a fair comparison and for the ease of setup, the EUT was placed at the bottom left corner of the cell.

\section{NumericAl RESUltS AND Discussion}

This section deals with the guiding idea behind the work followed by the results of the empirical study for its further investigation and validation. The initial study comes from immunity testing. Hence, norms of $\|\mathrm{E}\|$ - and $\|\mathrm{H}\|$-fields were simulated for an input power of $1 \mathrm{~W}$ with a $50 \Omega$ load at the TEM cell ports. Conversely, the validation of the idea was carried out thanks to emission testing, where both ports of the cell were terminated with $50 \Omega$ while the radiator (a patch antenna) was fed by a $1 \mathrm{~W}$ source.

In both cases, for a fair comparison of EM field distributions and to compensate for the mismatch, the results were then normalized to have the same matching level for the considered scenarios at the corresponding resonant frequencies. The EM field distributions were monitored at locations where EUTs are 
usually placed in TEM cells (i.e. at the top and bottom of the closed and open cells, respectively). According to simulations, only a TEM mode propagates below $1 \mathrm{GHz}$ and $0.75 \mathrm{GHz}$ in the closed and open TEM cells, respectively, while higher order modes coexist beyond those frequencies; a similar result was reported in [14].

In the immunity simulations, two adjacent resonance frequencies of the cells were considered, one below and another beyond their corresponding dominant mode frequencies (i.e. 0.9 and $1.4 \mathrm{GHz}$ for the closed cell, and 0.53 and $0.88 \mathrm{GHz}$ for the open one), in order to be able to find out the impact of frequency and presence of higher order modes. On the contrary, the emission simulations were carried out at the operating frequency of the chosen radiator (i.e. $2.475 \mathrm{GHz}$ ).

\section{A. Basic Idea}

The guiding idea behind the paper stems from the fact that during a recent experiment using an open TEM cell, while
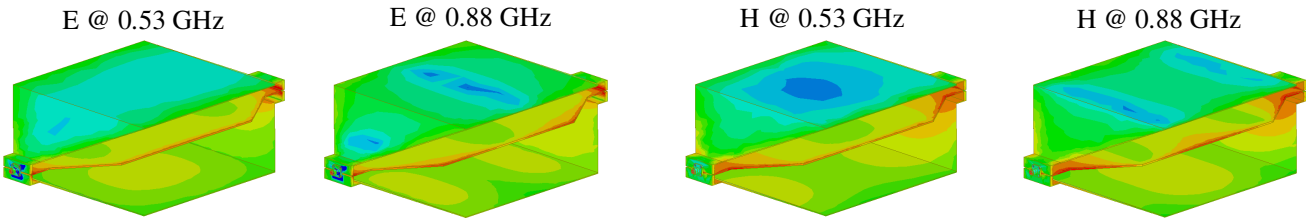

(a)
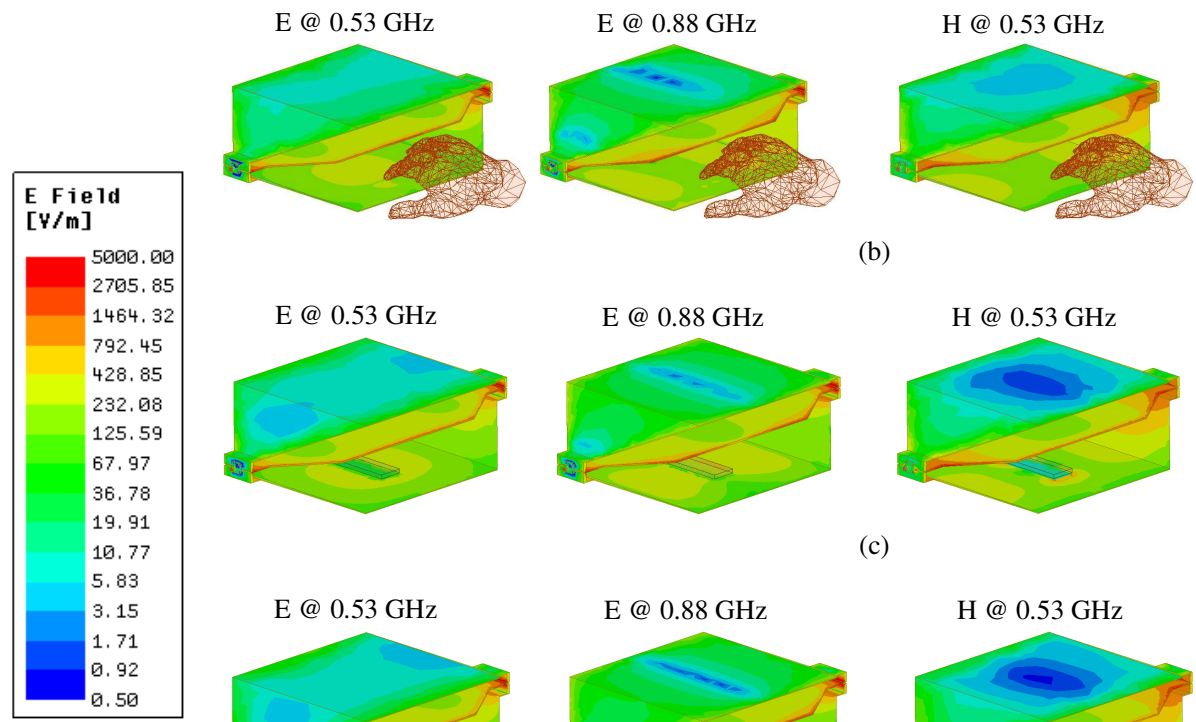

(b)
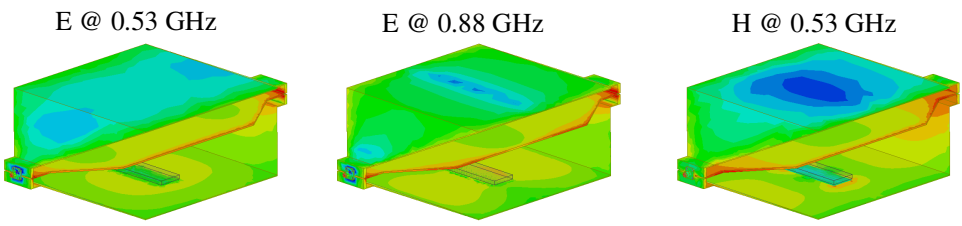

(c)
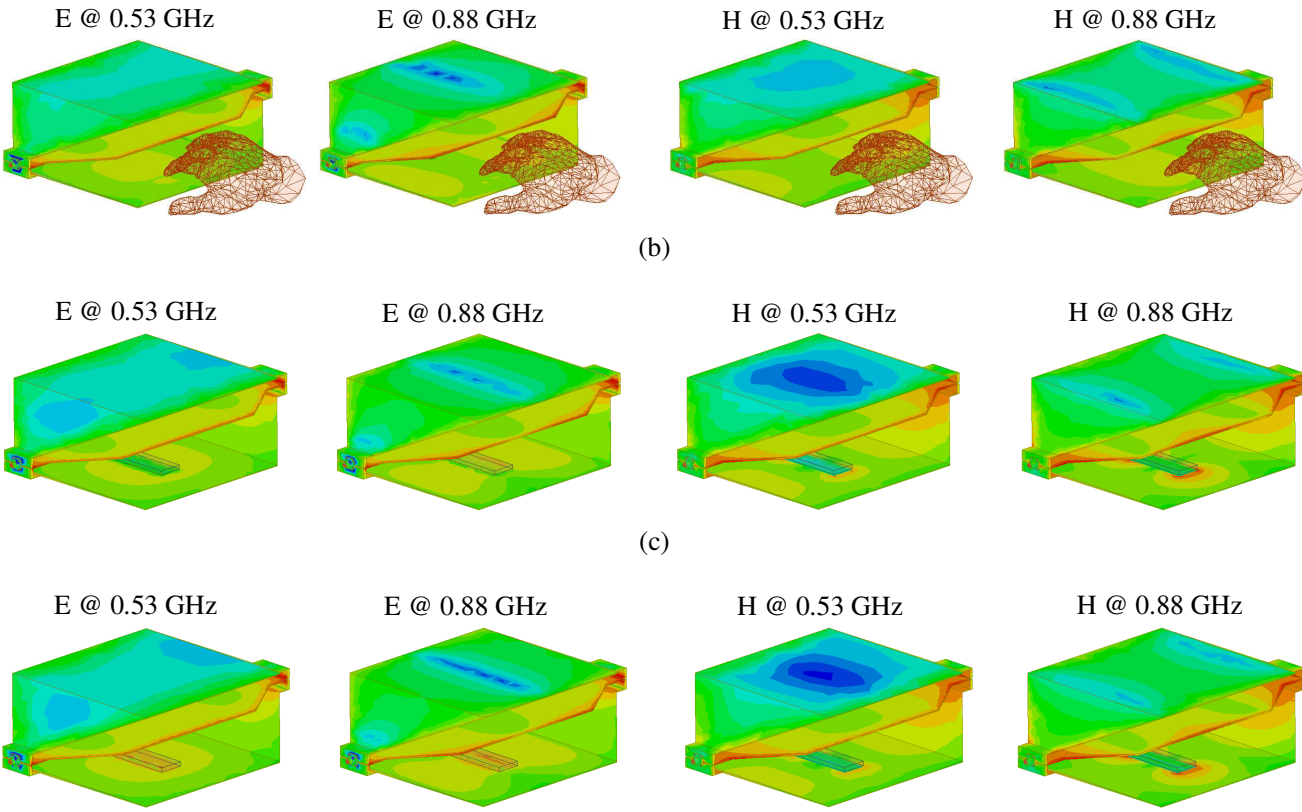

changing the PCB orientation, we noticed that the presence of our hand did not disturb the measurements to characterize the EUTs emission frequencies. This made us think about how EM fields could influence the TEM cells behavior.

A similar exposure scenario was considered with the human hand in proximity to an open TEM cell in the absence of the EUT, to see how the EM field behaves (Fig. 11a). To be able to make a comparison of the results in presence and absence of the hand, we firstly simulated both $\|\mathrm{E}\|$ - and $\|\mathrm{H}\|$ field distributions inside a standard open TEM cell (TBTC1 [22], Fig. 2a). The latter was then loaded by the presence of a human hand; results are shown in Fig. 2p. Note that:

- since field distributions do not change according to any $x y$ plane, E- and H-fields which are always in $z$ and $x$ directions, respectively, are plotted at the cell's bottom level only; any change of distribution in this plane helps distinguishing the results from one scenario to another

- the colors representing the field distribution in logarithmic
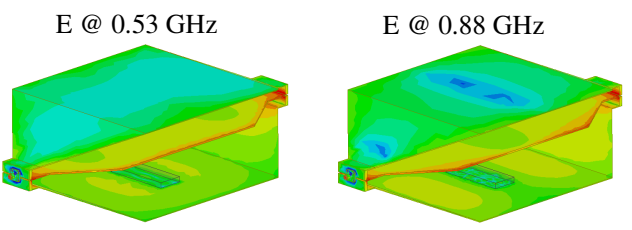

(d)
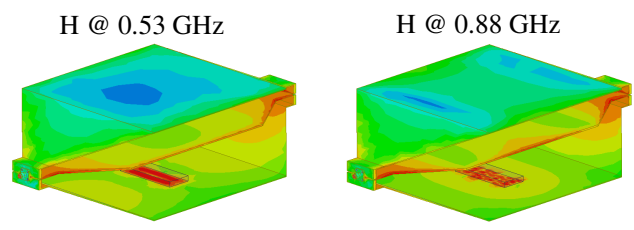

(e)

Fig. 2. Simulated $\|\mathrm{E}\|$ - and $\|\mathrm{H}\|$-field distributions inside an open TEM cell for $1 \mathrm{~W}$ input power: (a) unloaded, (b) in presence of a human hand; (c) loaded by a small piece of ferrite $\left(\varepsilon_{r}=12, \mu_{r}=1000\right)$; (d) loaded by a small piece of ferrite $\left(\varepsilon_{r}=1, \mu_{r}=1000\right)$; (e) loaded by a small piece of Plexiglas $\left(\varepsilon_{r}=1000, \mu_{r}=1\right)$. 
scale go from dark blue (low current density) to green to yellow to red (high current density)

As observed, in line with our expectations, the hand presence locally disturbs the $\|\mathrm{E}\|$ distribution whereas it has a small effect on $\|\mathrm{H}\|$ at the hand location when compared to those obtained in the unloaded cell. This may imply that inside open TEM cells $\|\mathrm{H}\|$-field coupling plays a stronger role compared to $\|\mathrm{E}\|$, as the hand presence (as a dielectric) has only a local effect on $\|\mathrm{E}\|$.

To further investigate this, we placed a small piece of a ferrite material $\left(\varepsilon_{r}=12, \mu_{r}=1000\right)$ inside the open TEM cell at the location where the hand was previously present to see how it impacts the EM fields; results are shown in Fig. 26. As it can be seen, presenting the ferrite not only disturbs the $\|\mathrm{H}\|$ but also the $\|\mathrm{E}\|$-field distributions in the cell. Unlike at frequencies lower than the dominant mode frequency where the presence of the ferrite only locally perturbs both $\|\mathrm{E}\|$ and $\|\mathrm{H}\|$, at higher frequencies it changes their distributions at the whole bottom of the cell. In order to check whether the disturbance in the $\|\mathrm{E}\|$-field distribution is related to the permittivity of ferrite, although not physically possible, we considered in simulation a case where the ferrite permittivity is set to $\varepsilon_{r}=1$ while keeping its permeability unchanged $\left(\mu_{r}=1000\right)$; results are shown in Fig. 2d. As observed, the $\|\mathrm{E}\|$ - and $\|\mathrm{H}\|$-field distributions are almost insensitive to the permittivity modification in the considered frequencies. It is worth mentioning that the influence of ferrite dimensions (increasing thickness from 6 to $20 \mathrm{~mm}$ and area from $76.2 \mathrm{~mm} \times 28.6 \mathrm{~mm}$ to $105 \mathrm{~mm} \times 58 \mathrm{~mm}$ ) was checked through simulations and found to follow the same observations on the EM field distributions inside the cell.

For a fair comparison, a "virtual" dielectric material of $\varepsilon_{r}=1000$ permittivity and unit permeability was also simulated (Fig. 2e), demonstrating that it has only a very local influence on both $\|\mathrm{E}\|$ and $\|\mathrm{H}\|$. After all, in order to significantly perturb the $\|\mathrm{E}\|$-field, the thickness of the Plexiglas was increased from 6 to $20 \mathrm{~mm}$ observing hardly any difference (results are not shown here due to minor changes).

To conclude, these results show that, independently of
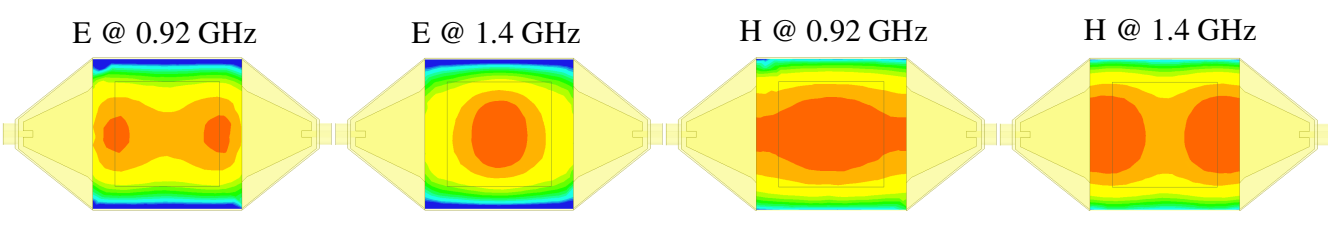

(a)
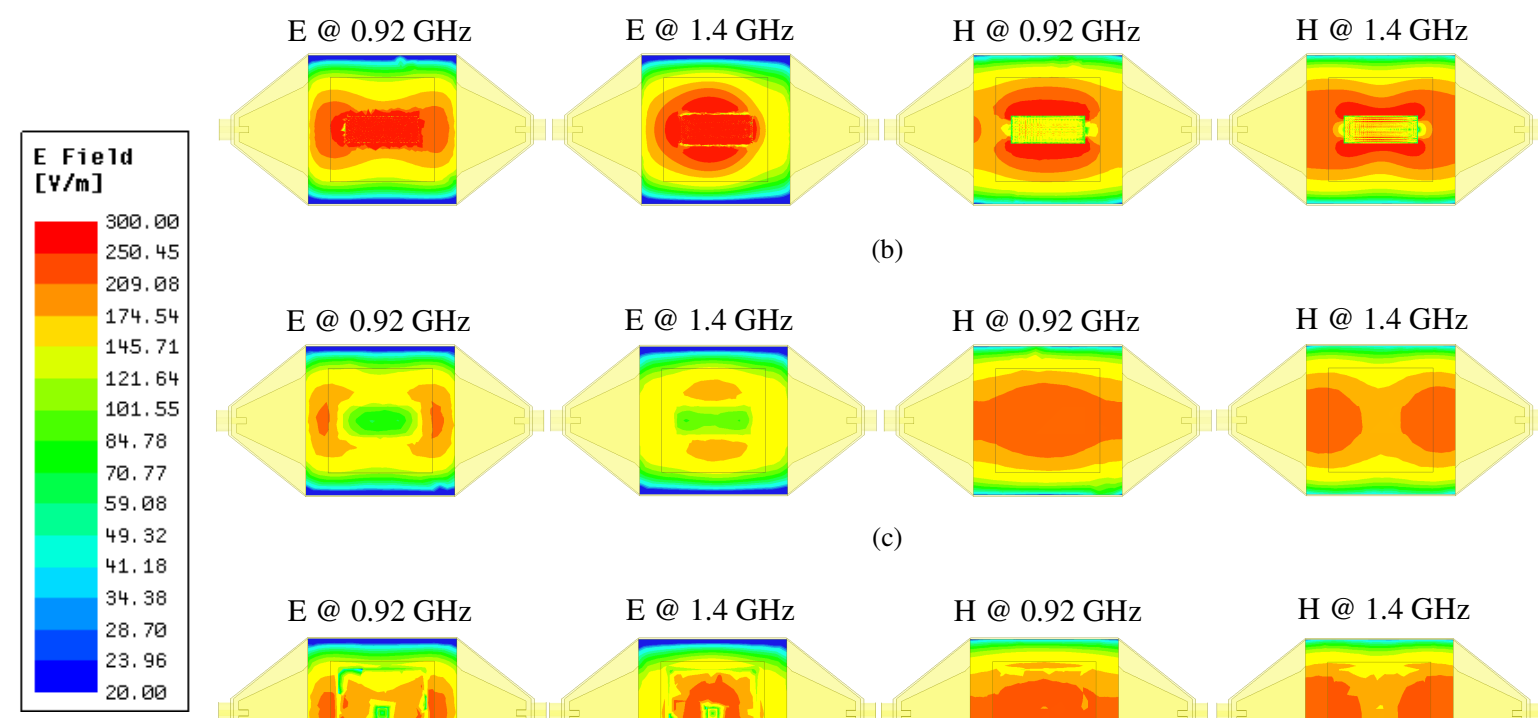

(b)
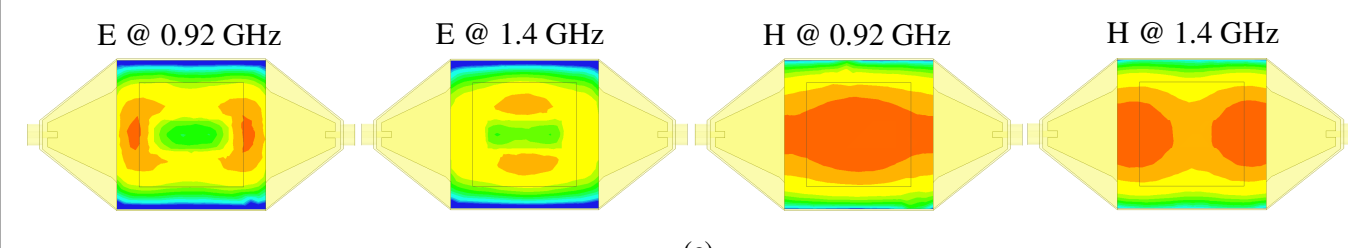

(c)

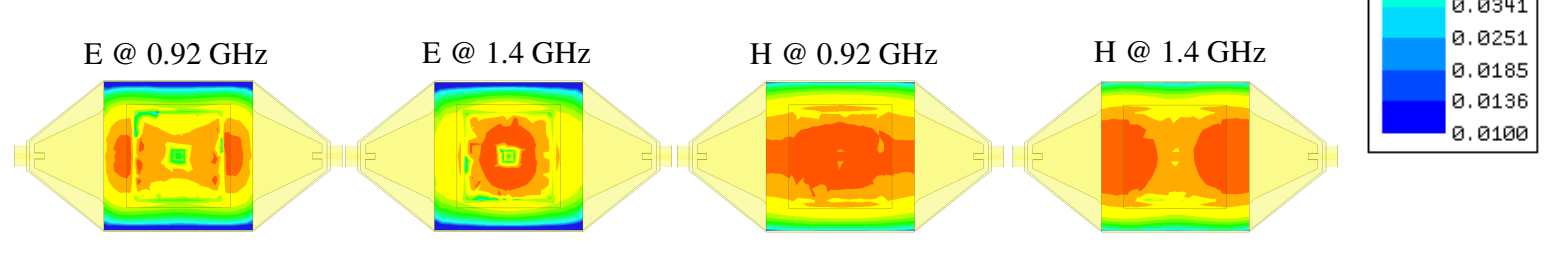

(d)

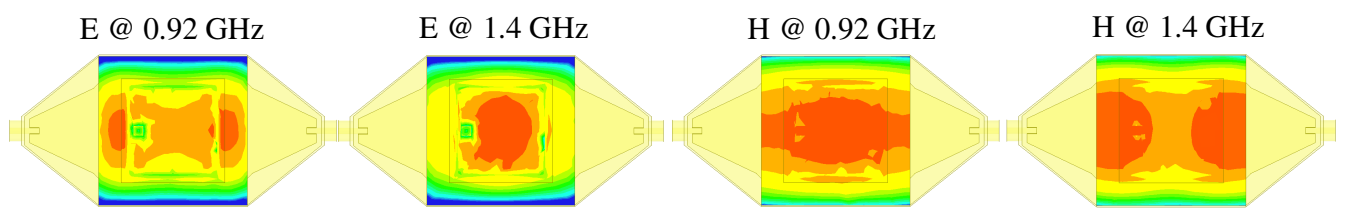

(e)

Fig. 3. Simulated $\|\mathrm{E}\|$ - and $\|\mathrm{H}\|$-field distributions inside a closed TEM cell for an input power of $1 \mathrm{~W}$ at its two first resonance frequencies: (a) unloaded; (b) loaded with ferrite; (c) loaded with Plexiglas; (d) loaded with the IEC PCB and a $1 \mathrm{~cm} \times 1 \mathrm{~cm}$ IC in the center; (e) similar to (d) with the IC shifted towards its side along the cell main axis.

\section{ACCEPTED MANUSCRIPT}


frequency and even in presence of higher order modes, loading an open TEM cell with a dielectric (such as the human hand) can only locally modify the $\|\mathrm{E}\|$ distribution (and $\|\mathrm{H}\|$ for a very high $\varepsilon_{r}$ value) whereas a ferromagnetic material (like ferrite) can alter both $\|\mathrm{E}\|$ and $\|\mathrm{H}\|$ distributions, locally (below the dominant mode frequency) or in the cell bottom where EUTs are usually placed (above that frequency). This is convincing enough to draw a conclusion about the relative $\|\mathrm{E}\|$ - and $\|\mathrm{H}\|$-field influences inside open TEM cells, i.e. "a local and significant $\|\mathrm{H}\|$-field distortion has a stronger impact than a local and significant $\|\mathrm{E}\|$-field distortion. In other words, the local $\|\mathrm{H}\|$-field distortion couples to the TEM cell in such a way that the wave propagation is dramatically altered".

In order to gain a deeper understanding, since there is supposed to be a linearly-polarized plane wave inside the TEM cell, and the wave experiences different media in presence of the considered materials, the power reflection and transmission mechanisms are different. We considered the power reflection $(\Gamma)$ and transmission $(\mathrm{T})$ coefficients based on the intrinsic impedance of the air-Plexiglas and air-ferrite interfaces; for air $\left(\varepsilon_{r}=1, \sigma=0\right)$ - Plexiglas $\left(\varepsilon_{r}=3.4, \sigma=0\right)$ interface $\Gamma$ and $\mathrm{T}$ are $8.8 \%$ and $91.2 \%$, whereas for the air ferrite $\left(\varepsilon_{r}=12, \sigma=\right.$ $\left.0.01 \mathrm{~S} / \mathrm{m}, \mu_{r}=1000\right) \Gamma$ significantly increases to $64.4 \%$ while $\mathrm{T}$ decreases to $35.6 \%$. This justifies the stronger distortion in the cell due to the ferromagnetic rather than the dielectric materials. As far as Plexiglas is concerned, the traveling wave passes almost entirely in the block across the whole frequency range of the cell leading to minimal disturbances (only locally around the block). Conversely, with a ferrite, at frequencies above the dominant mode, not only the fundamental wave is perturbed due to the high amount of reflected power but also all higher order modes, which leads to a global distortion in the cell. More generally speaking, a ferrite offers larger (normal) electric field and (tangential) magnetic field discontinuities at the boundaries, inducing secondary sources.

For the sake of completeness and to support that main finding, further simulations in presence of ferromagnetic and dielectric materials were performed:

- to see whether it is valid inside closed TEM cells

- to assess the influence of an IC mounted on a PCB on field distribution

- to compare the results with practical measurements

For a fair comparison, small rectangular-shaped pieces of ferrite and Plexiglas of the same dimensions $(76.2 \mathrm{~mm} \times$ $28.6 \mathrm{~mm} \times 6.35 \mathrm{~mm}$ ), shown in Fig. 1, were used in simulations and measurements.

Fig. 3 exhibits the $\|\mathrm{E}\|$ - and $\|\mathrm{H}\|$-field distributions inside a closed TEM cell (FCC-TEM-JM2 [25]). Similar observations to those with an open cell can be made:

- whatever the frequency and the propagating modes, unlike ferrite that modifies both $\|\mathrm{E}\|$ and $\|\mathrm{H}\|$ distributions when compared to an unloaded cell, Plexiglas only changes $\|\mathrm{E}\|$

- therefore, an $\|\mathrm{H}\|$-field distortion is more significant than a $\|\mathrm{E}\|$-field distortion inside closed cells

What is interesting is that the locations of both $\|\mathrm{E}\|$ and $\|\mathrm{H}\|$ maxima vary with frequency, resulting in field inhomogeneity even just below the dominant mode. Therefore, in TEM cell measurements where a non-dielectric EUT (such as a piece of wire as a transmission line over the PCB intended for field evaluation purposes) is located at the center of the PCB, practical results would not always correspond to the most important disturbance within the cell (that can be seen at 0.92 and $1.4 \mathrm{GHz}$ for $\|\mathrm{E}\|$ and $\|\mathrm{H}\|$, respectively). This implies that, depending on frequency, caution has to be taken for testing using closed TEM cells. Moreover, it can be stated that the presence of an IC on the IEC 62132-2 standard PCB [7] changes dramatically the field distribution. In particular, it reduces the field magnitudes around the IC pins and even more in the IC package (Fig. $3 \mathrm{~d}$ ). What can also be noticed is that field magnitudes at IC location are the same regardless of its position on the PCB, despite the fields being nonuniform within the cell (Fig. 33). The latter corroborates the fact that measurements could overestimate IC immunity at pin locations by about $30 \%(145 \mathrm{~V} / \mathrm{m}$ instead of $210 \mathrm{~V} / \mathrm{m}$, Fig. 3 d $)$ compared to the maximum field available in the TEM cell. It is also worth mentioning that, according to simulations, the wave impedance inside both unloaded closed and open TEM cells where the EUT is usually placed is partially beyond $377 \Omega$, up to $511 \Omega$; a fact corroborated in [20].

Note that to have an idea of how relocating the materials inside the open cell influences the EM field distributions at its resonance frequencies as well as the same frequencies used in emission measurements (138.5 MHz and $2.475 \mathrm{GHz}$ ), results are depicted and discussed in the Appendix.

\section{B. Proof of Concept}

In order to assess the open TEM cell behavior in emission testing with a setup comparable to the one intended to be
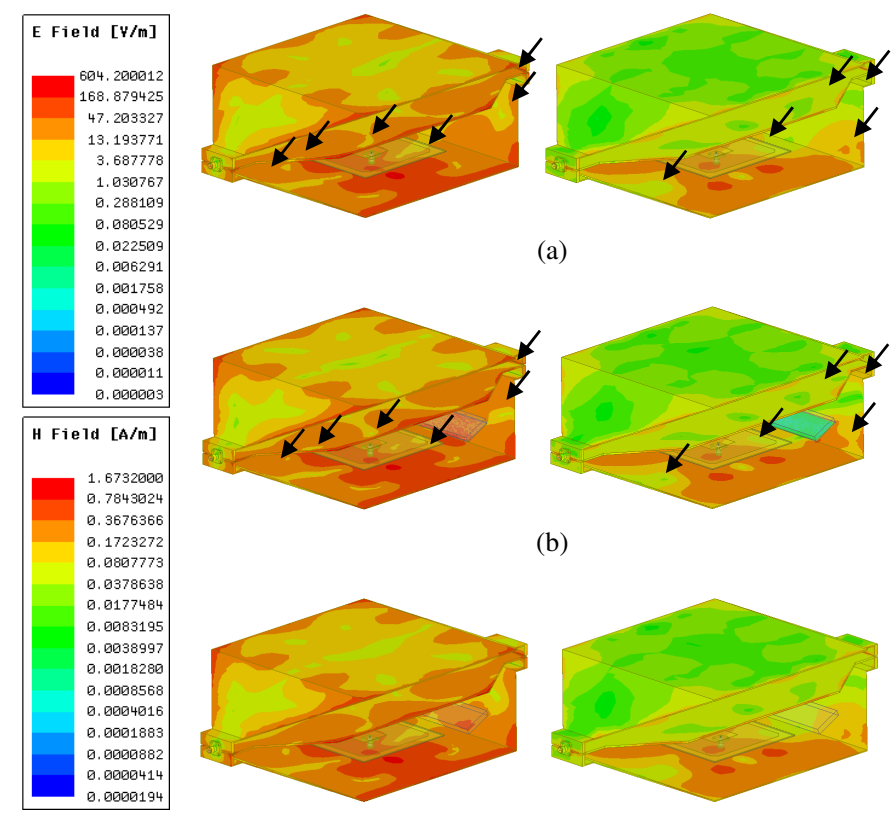

(a)
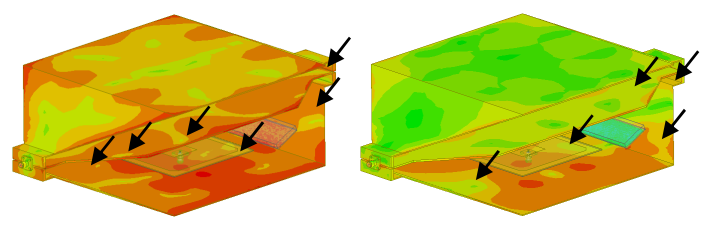

(b)
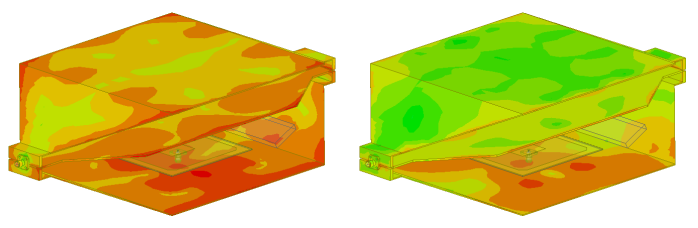

(c)

Fig. 4. Simulated $\|\mathrm{E}\|$ - (left) and $\|\mathrm{H}\|$-field (right) distributions inside an open TEM cell in presence of a patch antenna radiating at $2.475 \mathrm{GHz}$ : (a) unloaded, (b) loaded with ferrite; (c) loaded with Plexiglas. Arrows indicate the locations of field distribution discrepancies among all cases. 


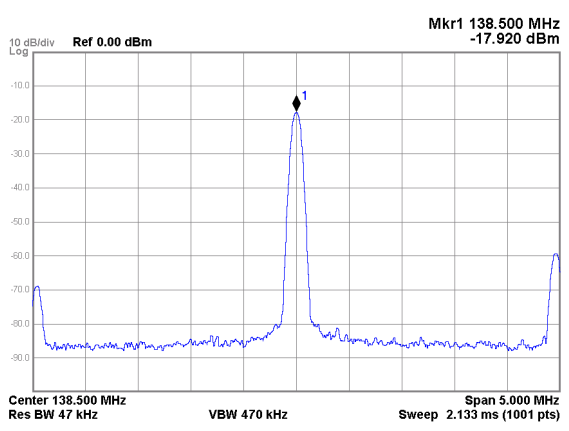

(a)

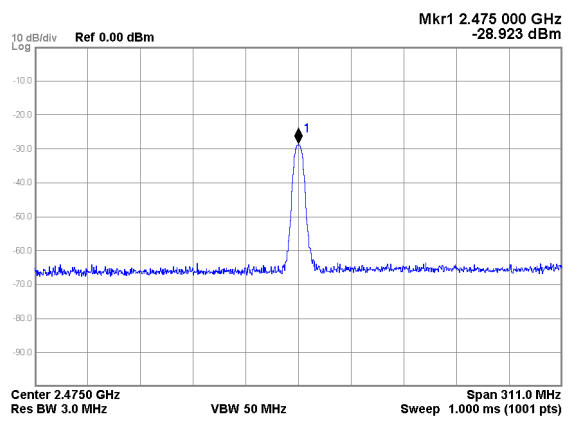

(d)

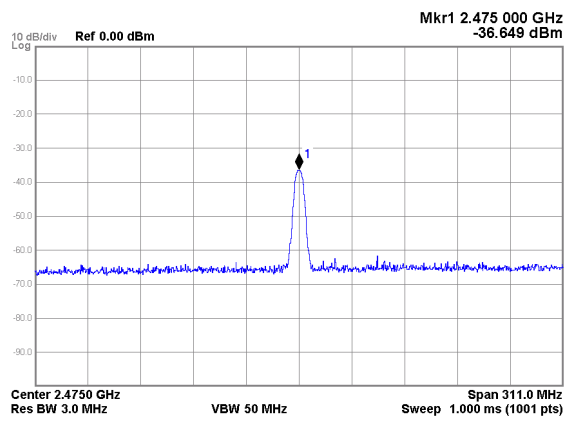

(g)

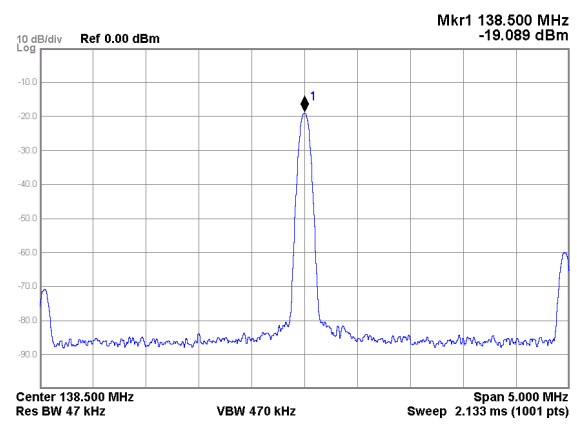

(b)

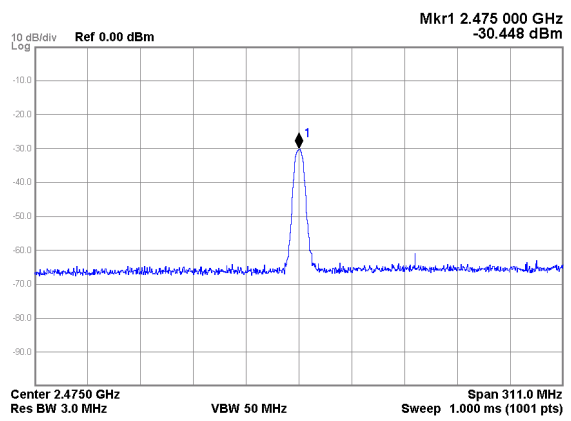

(e)

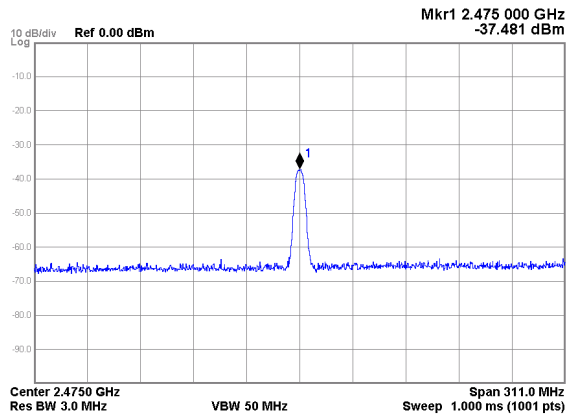

(h)

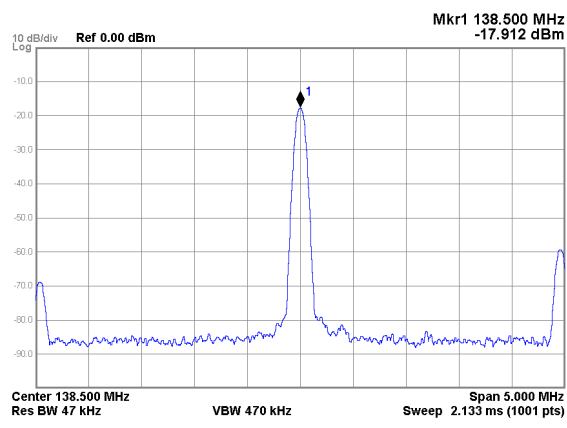

(c)

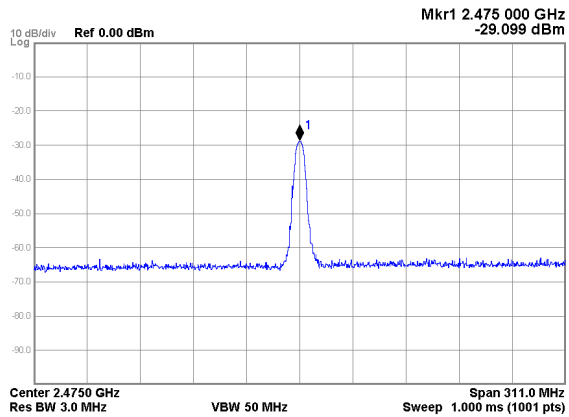

(f)

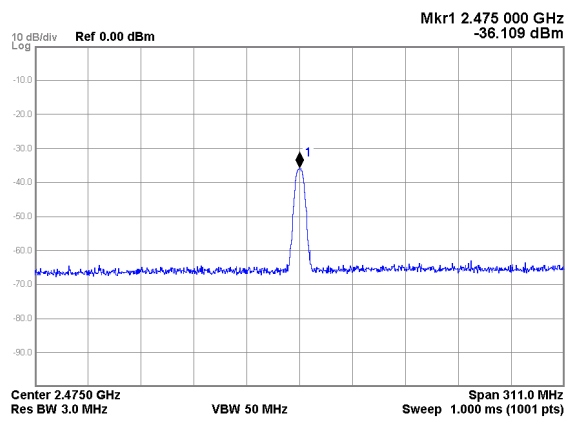

(i)

Fig. 5. Measured radiated emission using an open TEM cell of (a-c) a Kiwi Millenium $\mu \mathrm{C}$ at $138.5 \mathrm{MHz}$; (d-f) and (g-i) a SAMR21 $\mu \mathrm{C}$ at $2.475 \mathrm{GHz}$ with a EUT placed at a peak and a null location, respectively: (left) unloaded; (middle) loaded with ferrite; (right) loaded with Plexiglas.

used in measurements later, simulations were carried out at $2.475 \mathrm{GHz}$ with the patch antenna as the radiator. Fig. 4 shows both $\|\mathrm{E}\|$ - and $\|\mathrm{H}\|$-field distributions. As observed, in those simulations, totally similar conclusions to those drawn in immunity simulations can be made, except that no reduction around the IC pins can be noticed.

\section{EXPERIMENTAL RESUlTS AND DisCUSSION}

The emissions of both "Kiwi Millenium" transmitter and SAMR21 $\mu \mathrm{C}$ were measured using an open TEM cell where the EUTs were placed firstly at a peak and then at a null location; results are shown in Fig. 5 a to 5 and at the same time summarized in Table I in terms of frequency and maximum received power levels for improved readability. In order to characterize those two locations, the EUT was slightly moved along the cell central $y$-axis while monitoring the level of the signal. Note that, at $2.475 \mathrm{GHz}$, due to the fast wave traveling at the chosen frequency, $1 \mathrm{~mm}$ steps and a $1 \mathrm{~cm}$ range were enough to ensure finding the maximum and minimum power levels.

As can be seen in Fig. 5k, at $138.5 \mathrm{MHz}$ where only the TEM mode is present, the presence of dielectric material has hardly any influence on the power levels collected by the cell $(-17.9 \mathrm{dBm})$ and, consequently, the field distribution in the TEM cell. Conversely, a $1.2 \mathrm{~dB}$ decrease in power level was observed with the ferromagnetic material (Fig. 5p).

Moreover, it can be seen in Fig. 5 that those results are also valid at $2.475 \mathrm{GHz}(0.8$ and $1.5 \mathrm{~dB}$ at the null and peak, respectively, although the ferrite is supposed not be operational at that frequency). Note that the decrease was even more pronounced with the ferrite getting closer to the EUT (up to $6 \mathrm{~dB}$ for $1 \mathrm{~cm}$ close proximity), whereas a minor change was noticed with the Plexiglas at the same location. This is due to the fact that Plexiglas has a local influence on EM field distributions, whereas the ferrite changes the distributions in the entire bottom of the cell. These results are in line with the 
TABLE I

MEASURED POWER LEVELS (IN DBM) FOR THE CONSIDERED SCENARIOS

\begin{tabular}{cccc}
\hline \hline Scenarios & $\begin{array}{c}\text { Unloaded } \\
\text { cell }\end{array}$ & $\begin{array}{c}\text { Cell loaded } \\
\text { with Ferrite }\end{array}$ & $\begin{array}{c}\text { Cell loaded } \\
\text { with Plexiglas }\end{array}$ \\
\hline $138.5 \mathrm{MHz}$ & -17.9 & -19.1 & -17.9 \\
\hline $2.475 \mathrm{GHz}$, peak & -28.9 & -30.4 & -29.1 \\
\hline $2.475 \mathrm{GHz}$, null & -36.6 & -37.5 & -36.1 \\
\hline \hline
\end{tabular}

conclusions extracted from simulations at frequencies higher than the cell's dominant mode frequency.

Furthermore, measurements with and w/o paper were conducted; results are shown in Fig. 6 As can be seen, the presence of the paper has hardly any influence on the power level. This is in fact due to the $\|\mathrm{E}\|$-field being locally perturbed only in the close proximity of the EUT, which does not impact the measurements in emission testing. It can be expected from the simulation results that it would also have a tiny impact on immunity testing due to the low permittivity value of the paper.

Finally, in order to understand the impact of the considered materials on the cell input impedance and to have an idea of the material losses at the chosen frequencies, the scattering parameters were measured using a Keysight 8753 ES vector network analyzer; results are shown in Fig. 7 As observed, the presence of the materials does not detune the cell input reflection coefficient. Moreover, ferrite losses are negligible at $138.5 \mathrm{MHz}$ (the $S_{21}$ parameter is unchanged, Fig. 77 and, therefore, can not explain by themselves the difference in the measured power levels (Fig. 5). Even though there is a $0.8 \mathrm{~dB}(1.5 \mathrm{~dB})$ difference in power levels at the null (peak) at $2.475 \mathrm{GHz}$, the difference in $S_{21}$ parameter is lower at that frequency $(0.65 \mathrm{~dB})$, reminding that it is outside of the ferrite operating range. The results were perfectly reproducible. They are in line with our expectations and clearly in agreement with all simulations performed previously.

\section{CONCLUSION}

A study of electromagnetic field distributions inside closed and open TEM cells was presented to figure out whether the presence of ferromagnetic and dielectric materials influences the field distributions, below and above the corresponding dominant modes of each cell. Simulations and measurements were performed at different frequencies (i.e. hundreds of $\mathrm{MHz}$ to $\mathrm{GHz}$ ) to assess the relative influence of the electric and magnetic fields generated or received by the cell when loaded by representative ferrite and Plexiglas materials.

First of all, just below the dominant mode and not only above, the inhomogeneity of both fields should be taken into account in order to assess the immunity level of an EUT. It was demonstrated that it is actually feasible to use the cells between the cutoff frequency and the upper frequency, provided that inhomogeneity is considered in the field levels. Note that, in the case of the open cell, it is possible to relocate the EUT at a peak in order to enhance field magnitude for a given input power. That result demonstrates that VSWR cannot be the only criterion limiting the operating range of a TEM

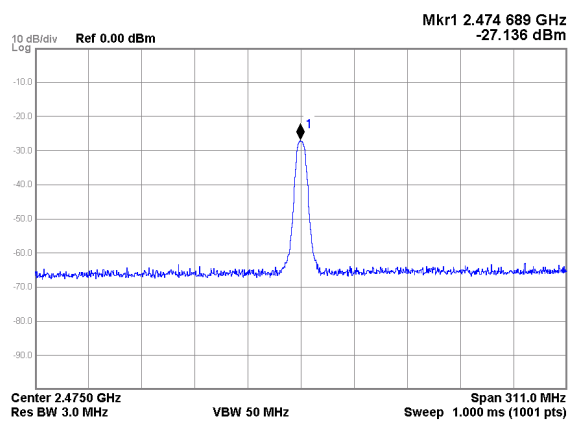

(a)

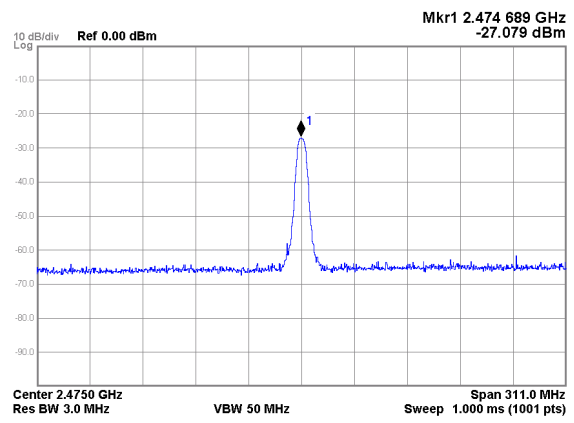

(b)

Fig. 6. Radiated emission measurements at $2.475 \mathrm{GHz}$ with a SAMR $21 \mu \mathrm{C}$ at the bottom corner of an unloaded open TEM cell: (a) with and (b) w/o paper.

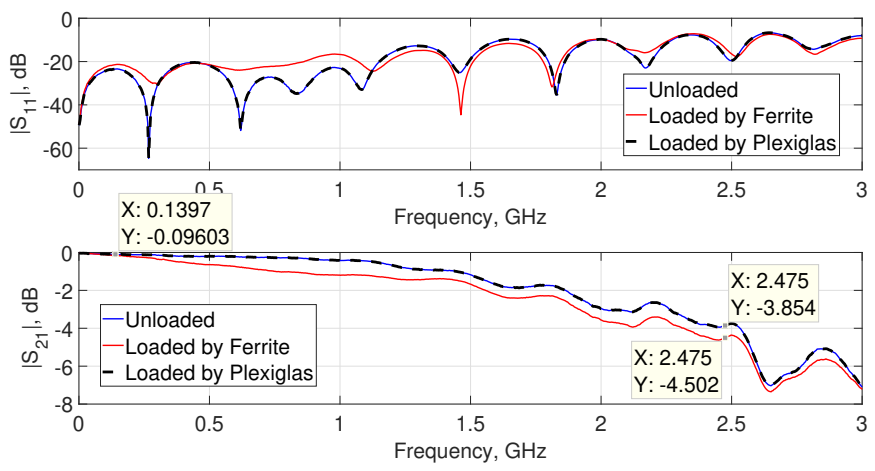

Fig. 7. Measured reflection and transmission coefficients of the open TEM cell without any material, with ferrite, and with Plexiglas.

cell: the dominant mode frequency must be determined, and measurements, while being feasible above that frequency, must be carefully rescaled according to field levels.

Then, experiments with materials resulted in the following: independently of frequency and EUT location, unlike the dielectric which only locally changes $\|\mathrm{E}\|$ (and $\|\mathrm{H}\|$ depending on permittivity) at the material location, the presence of a ferromagnetic material inside the cell changes both $\|\mathrm{E}\|$ and $\|\mathrm{H}\|$ distributions: locally below the dominant mode frequency and globally at the entire bottom of the cell above that frequency. This clearly demonstrates that a local distortion of $\|\mathrm{H}\|$-field, due to a ferromagnetic material, has a stronger influence than a local distortion of $\|\mathrm{E}\|$-field inside both closed and open TEM cells, disregarding frequency, location and magnetic losses.

To sum up, the demand to use a TEM cell below the

\section{ACCEPTED MANUSCRIPT}



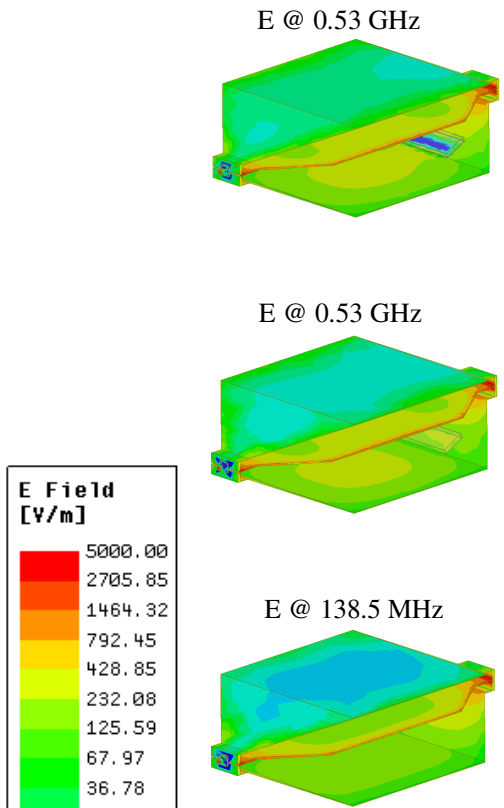

E@ $138.5 \mathrm{MHz}$

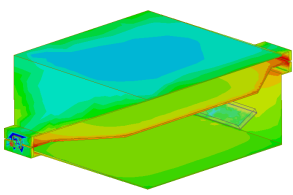

E@ $138.5 \mathrm{MHz}$

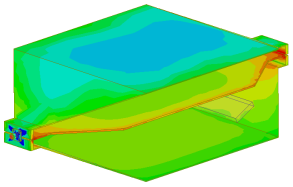

E@0.88 GHz

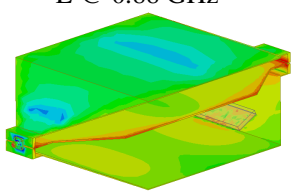

E@ $0.88 \mathrm{GHz}$

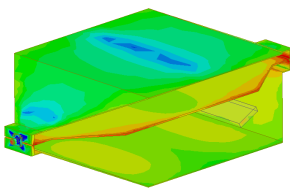

E @ $2.475 \mathrm{GHz}$
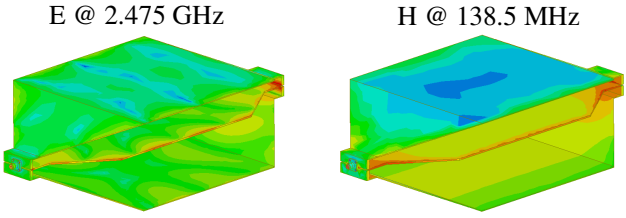

(c)

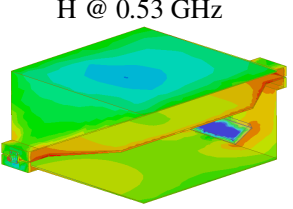

(a)

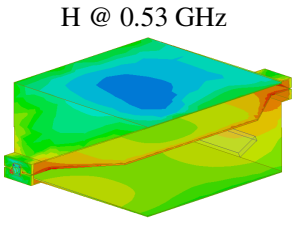

(b)

E @ $2.475 \mathrm{GHz}$

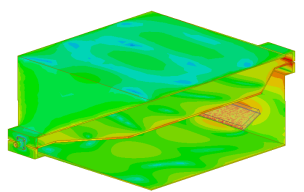

H@138.5 MHz

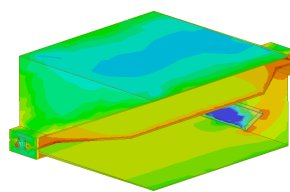

(d)
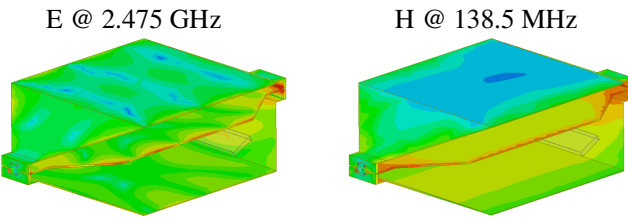

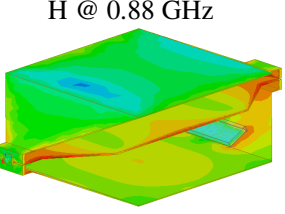

H @ $0.88 \mathrm{GHz}$

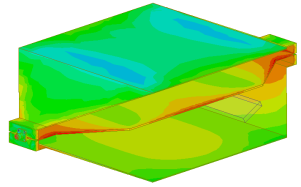

\section{H Field}

$[\mathrm{A} / \mathrm{m}]$

H@2.475 GHz

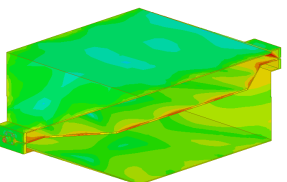

H @ 2.475 GHz

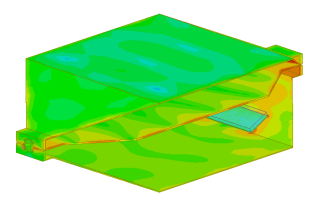

H @ $2.475 \mathrm{GHz}$

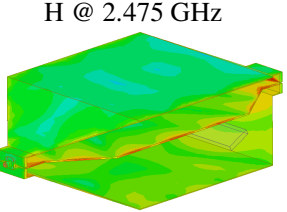

(e)

Fig. 8. Simulated $\|\mathrm{E}\|$ - and $\|\mathrm{H}\|$-field distributions inside an open TEM cell for an input power of $1 \mathrm{~W}$ at different frequencies: (a) and (d) loaded with ferrite; (b) and (e) loaded with Plexiglas; (c) unloaded.

dominant mode frequency, as mentioned in the IEC 61967-2 and 62132-2 standards, may not be relevant, provided that both EM field inhomogeneities are considered, and the presence of an IC package in the cell is accounted for in the equivalent $\|\mathrm{E}\|$-field level obtained around the pins in immunity testing for a given input power whatever the frequency.

\section{APPENDIX}

Fig. 8 shows the EM field distributions inside an open TEM cell when loaded by ferrite and Plexiglas placed near the cell input port at the cell first two resonances and the emission frequencies of both EUTs (138.5 MHz and 2.475 GHz). As can be seen, similar observations and explanations to those given in Section III-A for the materials located in the TEM cell center can be made.

\section{ACKNOWLEDGMENT}

The authors would like to cordially thank Prof. A. Alves Moreira for the fruitful discussions. We also thank V. Arboux for his assistance with prototype construction.

\section{REFERENCES}

[1] S. Ben Dhia, M. Ramdani, E. Sicard, "Electromagnetic Compatibility of Integrated Circuits: Techniques for low emission and susceptibility," ISBN 978-0-387-26601-5, Berlin: Springer, 2006.

[2] V. S. Reddy, P. Kralicek, and J. Hansen, "A novel segmentation approach for modeling of radiated emission and immunity test setups," IEEE Trans. Electromag. Compatibility, vol. 59, no. 6, pp. 1781-1790, 2017.

[3] F. Pythoud,"Proficiency testing in EMC radiated immunity," IEEE Trans. Electromag. Compatibility, vol. 60, no. 5, pp. 1249-1253, 2018.

[4] M. Ramdani, E. Sicard, A. Boyer, S. Ben Dhia, J. Whalen, T. Hubing, M. Coenen, and O. Wada, "The electromagnetic compatibility of integrated circuits - past, present, and future," IEEE Trans. Electromag. Compatibility, vol. 51, no. 1, pp. 78-100, 2009.

[5] Sh.-Y. Yuan, Y.-L. Wu, R. Perdriau, and Sh.-S. Liao, "Detection of electromagnetic interference in microcontrollers using the instability of an embedded phase-lock loop," IEEE Trans. Electromag. Compatibility, vol. 55, no. 2, pp. 299-306, 2013.

[6] IEC 61967-2: Integrated circuits, measurement of electromagnetic emissions, $150 \mathrm{kHz}$ to $1 \mathrm{GHz}$, Measurement of radiated emissions - TEM cell and wideband TEM cell method, 2005.

\section{ACCEPTED MANUSCRIPT}


[7] IEC 62132-2: Integrated circuits, measurement of electromagnetic immunity, $150 \mathrm{kHz}$ to $1 \mathrm{GHz}$, Measurement of radiated immunity - TEM cell and wideband TEM cell method, 2010.

[8] M. L. Crawford, J. L. Workman, "Using a TEM cell for EMC measurements of electronic equipment," US Department of Commerce, National Bureau of Standards, 1979

[9] M. Kanda, R. David Orr, "Generation of standard electromagnetic fields in a TEM cell," US Department of Commerce, National Bureau of Standards, 1988.

[10] D. E. Anagnostou, Organic paper-based antennas. "Innovation in Wearable and Flexible Antennas", chapter 2, WIT Press, 2014

[11] M. L. Crawford, "Generation of standard EM fields using TEM transmission cells," IEEE Trans. Electromag. Compatibility, vol. EMC-16, no. 4, pp. 189-195, 1974.

[12] K. Malaric, "Electromagnetic compatibility analysis using TEM cells," OSEE Online Symposium for electronic engineers, no. 14976, 2001.

[13] P. Kay, "Field distribution and over-moding in a TEM cell," 17th Int. Zurich Symp. Electromag.c Compatibility, Singapore, pp. 457-460, 2006.

[14] A. El Abbazi, "Etude et réalisation d'une nouvelle cellule TEM à support rotatif pour des mesures CEM des circuits intégrés: application du modéle ICEM,” Ph.D. dissertation, university of Rennes 1, 2006. [Online] https://tel.archives-ouvertes.fr/tel-00143891.

[15] N. Boriraksantikul, "A TEM CELL design to study electromagnetic radiation exposure from cellular phones," MS.C. dissertation, university of Missouri, 2008.

[16] P. F. Lopez, A. Ramanujan, Y. V. Gilabert, C. Arcambal, A. Louis and B. Mazari, "A radiated emission model compatible to a commercial electromagnetic simulation tool," 20th International Zurich Symp. Electromag. Compatibility, Zurich, Switzerland, pp. 369-372, 2009.

[17] C. Iftode, S. Miclaus, "Design and validation of a TEM cell used for radiofrequency dosimetric studies," Progress Electromag. Research, vol. 132, pp. 369-388, 2012.

[18] K. Kwak, J. Kim, J. Kim, "Near-field validation of dipole-moment model extracted from GTEM cell measurements and application to a real application processor," IEEE Trans. Electromag. Compatibility, vol. 60, no. 2, pp. 423-434, 2018.

[19] A. De Vita, R. Gaffoglio, B. Sacco, "Characterization of an open GTEM cell with the COMSOL multiphysics software," proc. COMSOL Conf., Lausanne, Switzerland, 2018.

[20] M. Koohestani, R. Perdriau, J.-L. Levant, and M. Ramdani, "A novel passive cost-effective technique to improve radiated immunity on PCBs," IEEE Trans. Electromag. Compatibility, early access, 2019.

[21] K. Satyaprasad, P. Siva Kumar, N. Deepika Rani, "Design and validation of transverse electromagnetic (TEM) cell for measurement of pulsed transients," Lecture Notes in Electrical Eng., vol 521, Springer, 2019.

[22] Tekbox TBTC1 TEM cell for EMC pre-compliance testing, Rekirsch Elektronik Inc. [Online] http://www.rekirsch.at/Tekbox+TBTC1.htm

[23] Ansys Inc., "High Frequency Structure Simulator (HFSS)," 2018, Electromagnetics Suite v19.1, Pittsburgh (PA), USA.

[24] S. Gabriel, R. W. Lau, and C. Gabriel, "The dielectric properties of biological tissues: II. Measurements in the frequency range $10 \mathrm{~Hz}$ to 20 GHz," Phys. Med. Biol., vol. 41, pp. 2251-2269, 1996.

[25] FCC-TEM-JM2 TEM cell, Fischer Custom Communications Inc. [Online] https://www.fischercc.com/products/fcc-tem-jm2

[26] Fair-Rite products corp. [Online] https://www.fair-rite.com/product/flatcable-emi-suppression-cores-2643164051/

[27] Kiwi Millenium version 4.5, Centre National d'Etudes Spatiales (CNES) [Online] https://www.planete-sciences.org/espace/IMG/pdf/manuel-kiwimillenium.pdf

[28] ATMEL SAMR21 low-power smart ARM-based wireless microcontroller. [Online] http://ww1.microchip.com/downloads/en/devicedoc/samr21-datasheet.pdf/

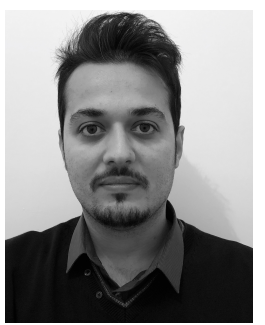

Mohsen Koohestani (S'13-M'15-SM'19) received the $\mathrm{PhD}$ degree (with honor) in electromagnetics from the École polytechnique fédérale de Lausanne (EPFL), Lausanne, Switzerland, and the Universidade de Lisboa (ULISBOA), Lisbon, Portugal, in 2014.

From 2014 to 2018, he was a Post Doctoral Fellow with the Institut d'Electronique et de Télécommunications de Rennes (IETR), Université de Rennes 1 , working mainly on biomedical applications of wireless power transfer systems (WPTs)

He is currently an Associate Professor at ESEO, Angers, France, in the field of RF electromagnetic. He is also an associate researcher at IETR. He has authored over 40 peer-reviewed scientific papers. His main field of research includes novel design and analysis of antennas and microwave components, design and characterization of human body models, dosimetry and exposure assessment, and WPT and energy harvesting.

$\mathrm{He}$ is a member of the France IEC standardization working group in the SC47A subcommittee on the EMC for integrated circuits.

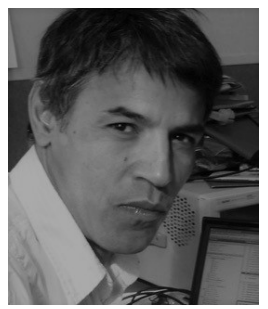

Mohamed Ramdani (M'01-SM'07) was born in Oujda, Morocco. He received the $\mathrm{PhD}$ Degree in Microelectronics from Université Paul Sabatier, Toulouse, France, in 1989, and the "Habilitation Diriger des Recherches" (Accreditation Degree) from Université de Rennes 1, France, in 2004.

From 1991 to 2008, he was an Associate Professor at ESEO, Angers, France, in the fields of microelectronics and microwave electronics. In 2008, he was promoted to Full Professor. His research interests are EMC of integrated circuits and integrated circuit design. He has authored several book chapters in EMC of ICs, and many peerreviewed scientific papers. Prof. Ramdani is a member of AFNOR (French section of the IEC). He served as General Chair of EMC Europe 2017, which was held in Angers, France. He was elected Vice-Chair of the IEEE France Section in 2016.

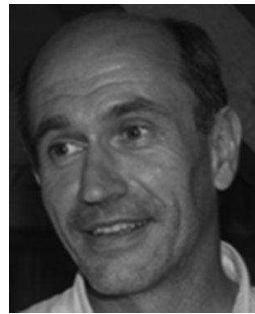

Philippe Besnier (M'04-SM'10) received the diplôme d'ingénieur degree from école universitaire d'ingénieurs de Lillle (EUDIL), Lille, France, in 1990 and the $\mathrm{Ph}$. D. degree in electronics from the university of Lille in 1993. Following a one year period at ONERA, Meudon as an assistant scientist in the EMC division, he was with the laboratory of radio-propagation and electronics (LRPE), University of Lille, as a researcher (chargé de recherche) at the Centre National de la Recherche Scientifique (CNRS) from 1994 to 1997. From 1997 to 2002, Philippe Besnier was the director of Centre d'Etudes et de Recherches en Protection Electromagnétique (CERPEM): a non-for-profit organization for research, expertise and training in EMC and related activities, based in Laval, France. He also co-founded TEKCEM in 1998, a small business company specialized in turn-key systems for EMC measurements. Back to CNRS in 2002, he has been since then with the Institute of Electronics and Telecommunications of Rennes (IETR). Philippe Besnier was appointed as CNRS senior researcher (directeur de recherche au CNRS) in 2013. He was co-head of the "antennas and microwave devices research department of IETR between 2012 and 2016. He headed the WAVES (electromagnetic waves in complex media) team during the first semester of 2017. Since July 2017, he is now a deputy director of IETR. His research activities are mainly dedicated to interference analysis on cable harnesses (including electromagnetic topology), theory and application of reverberation chambers, near-field probing and uncertainty quantification in EMC modeling. 


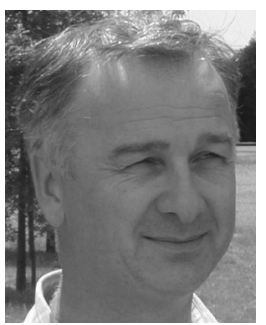

Jean-Luc Levant received the $\mathrm{PhD}$ degree from Institute National des Sciences Appliques (INSA), Rennes, France, in 2007. He is currently working in Microchip as a senior EMC expert. His main research interests include ICs modeling, power and signal integrity, and electrical fast transient analyses.

$\mathrm{He}$ is a member of the IEC standardization working group in the SC47A subcommittee on the EMC for integrated circuits.

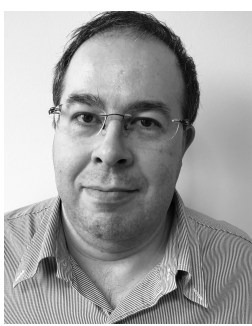

Richard Perdriau (M'01-SM'07) was born in Angers, France, in 1971. He received the Engineering Degree in Electronics and Computer Science from ESEO, Angers, in 1992, the PhD Degree in Applied Sciences from Université Catholique de Louvain, Louvain-la-Neuve, Belgium, in 2004, and the "Habilitation Diriger des Recherches" (Accreditation Degree) from Universit de Rennes 1, France, in 2012 .

From 1992 to 2012, he was an Associate Professor at ESEO, in the fields of microelectronics and embedded systems. In 2013, he was promoted to Full Professor. His research interests are EMC of integrated circuits, mixed-signal hardware description languages and integrated circuit design. He served as the Vice-Chair and Technical Program Co-Chair of EMC Europe 2017. 